\title{
Polysaccharides from Ganoderma lucidum attenuate microglia-mediated neuroinflammation and modulate microglial phagocytosis and behavioural response
}

Qing Cai ${ }^{1,2}$, Yuanyuan $\mathrm{Li}^{1,2}$ and Gang Pei ${ }^{1,3^{*}}$

\begin{abstract}
Background: Ganoderma lucidum (GL) has been widely used in Asian countries for hundreds of years to promote health and longevity. The pharmacological functions of which had been classified, including the activation of innate immune responses, suppression of tumour and modulation of cell proliferations. Effective fractions of Ganoderma lucidum polysaccharides (GLP) had already been reported to regulate the immune system. Nevertheless, the role of GLP in the microglia-mediated neuroinflammation has not been sufficiently elucidated. Further, GLP effect on microglial behavioural modulations in correlation with the inflammatory responses remains to be unravelled. The aim of this work was to quantitatively analyse the contributions of GLP on microglia.

Methods: The BV2 microglia and primary mouse microglia were stimulated by lipopolysaccharides (LPS) and amyloid beta $_{42}\left(A \beta_{42}\right)$ oligomer, respectively. Investigation on the effect of GLP was carried by quantitative determination of the microglial pro- and anti-inflammatory cytokine expressions and behavioural modulations including migration, morphology and phagocytosis. Analysis of microglial morphology and phagocytosis modulations was confirmed in the zebrafish brain.

Results: Quantitative results revealed that GLP down-regulates LPS- or A $\beta$-induced pro-inflammatory cytokines and promotes anti-inflammatory cytokine expressions in BV-2 and primary microglia. In addition, GLP attenuates inflammationrelated microglial migration, morphological alterations and phagocytosis probabilities. We also showed that modulations of microglial behavioural responses were associated with MCP-1 and C1q expressions.

Conclusions: Overall, our study provides an insight into the GLP regulation of LPS- and A $\beta$-induced neuroinflammation and serves an implication that the neuroprotective function of GLP might be achieved through modulation of microglial inflammatory and behavioural responses.
\end{abstract}

Keywords: Microglia, Ganoderma lucidum polysaccharides, Neuroinflammation, Behavioural response, Amyloid beta

\footnotetext{
* Correspondence: gpei@sibs.ac.cn

${ }^{1}$ State Key Laboratory of Cell Biology, Institute of Biochemistry and Cell Biology, Shanghai Institutes for Biological Sciences, Chinese Academy of Sciences, 320 Yueyang Road, Shanghai 200031, China

${ }^{3}$ School of Life Science and Technology, and the Collaborative Innovation

Center for Brain Science, Tongji University, Shanghai 200092, China

Full list of author information is available at the end of the article
} 


\section{Background}

Ganoderma lucidum is a well-known herb used in the traditional Chinese medicine to promote longevity and is beneficial for general health $[1,2]$. In recent years, the extract of Ganoderma lucidum (GL) has been isolated [3-5] and frequently used in medications as well as in dietary supplements. The constituents of GL include mainly ergosterol, triterpenoids, unsaturated fatty acids and polysaccharides. Amongst all, polysaccharides are the major pharmacologically active ingredient. The effects of GL extracts had been related to the promoted innate immune responses, suppression of cancer cell migration, as well as modulations of cell proliferations [6-8]. In recent years, studies have shown that GL exhibited neuroprotective effect and significantly attenuated amyloid beta $(\mathrm{A} \beta)$ peptide-induced neurotoxicity [9]. In addition, evidence showed that pre-administration of GL spores to rat might also protect the hippocampus from oxidative damages [10]. All of these provided positive implications for GL in the treatment of Alzheimer's disease (AD). Nevertheless, there have not been sufficient studies in the biochemical mechanism to which GLP might target AD.

The aetiology of $\mathrm{AD}$ is of complex mechanisms and not yet fully resolved. Two hallmarks characterising this neurodegenerative disease are the aggregation of $\mathrm{A} \beta$ leading to senile plaques and the progressive cognitive impairments [11]. In the central nervous system (CNS), deposition of $A \beta$ results into the activation of microglia, the resident immune cells and thus neuroinflammation [12]. Activated microglia release pro-inflammatory cytokines and neurotoxic mediators with altered cell behaviours, which may be characterised by the microglial morphology, migration and phagocytosis [13]. A positive feedback from microglial phagocytosis is the removal of dead neurones and neuronal debris, which in turn contributes to the attenuation of inflammatory stress. However, prolonged activation by Toll-like receptor (TLR) agonists, such as lipopolysaccharides (LPS), A $\beta$ and lipoteichoic acid, may result into aberrant phagocytosis process $[14,15]$. Under such conditions, microglia target on live neurones, neuronal progenitor cells (NPC) and glioma cells, all of which leads to neuronal loss in the CNS [14].

In the present study, we aimed to investigate the effect of GLP on the LPS- and A $\beta$-induced microglial behavioural changes. Apart from the pro-inflammatory mediators, chemokines such as MCP-1 also accumulate as a result of neuroinflammation. MCP-1 over-expression has been detected in many neurodegenerative diseases [16-18]. In the AD brain, the function of MCP-1 is related to cell movement and initiates monocyte accumulation at the site of $A \beta$ deposition [19-21]. The upregulation of MCP-1 expression may contribute to the chronic inflammation [22]. Our results revealed that GLP reduced the pro-inflammatory cytokines and MCP-1 expressions with a tendency to promote antiinflammatory cytokine levels. We also demonstrated that GLP modulation of microglial behavioural changes in vitro was associated to MCP-1 expressions. Finally, we confirmed the GLP-modulated microglial behavioural changes in vivo.

\section{Methods \\ Animals}

The current study was conducted in strict accordance with the guidelines of the Institute of Biochemistry and Cell Biology, Chinese Academy of Sciences. All experimental protocols in the study were approved and overseen by the Animal Care and Use Committee of the Shanghai Institute of Biochemistry and Cell Biology, Chinese Academy of Sciences. All mice (C57BL/6) were maintained in the pathogen-free conditions.

\section{Ganoderma lucidum polysaccharides}

The GL polysaccharides were provided by Shanghai Lugu Pharmaceuticals and were extracted from the dried conidial powder of GL according to previous protocol [23]. In brief, $1.35 \mathrm{~kg}$ of G. lucidum-dried conidial powder was defatted with $95 \% \mathrm{EtOH}$ for 1 week, followed by 5 -h boiling water extraction procedure for six repeated times. The supernatant was combined, concentrated and centrifuged. To the concentrated supernatant, three volumes of $95 \% \mathrm{EtOH}$ were added to precipitate the crude polysaccharides, CPW (28.2 g, 2\%). CPW (7 g) was then fractionated and eluted using distilled water to obtain the water extracts (3.25 g). This water extracts were further purified on a Sephacryl S-300 column $(2.6 \mathrm{~cm} \times 100 \mathrm{~cm})$ and eluted with $0.2 \mathrm{M} \mathrm{NaCl}$ to obtain GLP. By high-performance gel permeation chromatography (HPGPC) method, the relative molecular weight of GLP was estimated at approximately $15 \mathrm{kDa}$. After careful examinations by the Lowry method and m-hydroxydiphenyl method, it was confirmed the polysaccharides contained no trace of protein and uronic acid. One single preparation of GLP was performed for all experiments.

\section{$A \beta_{42}$ oligomer preparation}

The $A \beta_{42}$ oligomers were prepared based on protocols by Stine [24]. In brief, the HFIP (hexafluoroisopropanol)treated $\mathrm{A} \beta_{42}$ peptides (Anaspec) were resuspended in dimethyl sulfoxide followed by dilution to $100 \mathrm{mM}$ in Ham's F12. After incubation for $24 \mathrm{~h}$ at $4{ }^{\circ} \mathrm{C}$, the soluble $A \beta_{42}$ oligomers were obtained and centrifuged for $10 \mathrm{~min}$ at $14,000 \mathrm{~g}$. The integrity of $\mathrm{A} \beta_{42}$ oligomers were previously validated by atomic force electromicroscopy and western blot [25]. In addition, dot blots were 
performed to confirmation the oligomeric and fibrillar forms of $A \beta_{42}$ (Additional file 1: Figure S2).

\section{Cell culture and treatment}

BV2 cell lines were cultured and maintained in Dubelcco's Minimal Essential Medium (DMEM), with 10\% fetal bovine serum (FBS) supplement and $100 \mathrm{U} / \mathrm{ml}$ penicillin and $0.1 \mathrm{mg} / \mathrm{ml}$ streptomycin. Primary microglia were prepared from wild-type C57BL/6 mice on postnatal day 1. In brief, the mice' cortices and hippocampi were dissected and the meninges were carefully removed. The combined cortical and hippocampal tissues were dissociated into single cells by gentle scissoring and pipetting. The resultant suspension of cells was seeded to a T75 flask, cultured in DMEM supplemented with $10 \% \mathrm{FBS}$ and $100 \mathrm{U} / \mathrm{ml}$ penicillin and $0.1 \mathrm{mg} / \mathrm{ml}$ streptomycin. After 7-10 days, microglial cells were isolated from the astrocyte monolayer sheet by shaking.

In all in vitro assays, BV2 cells and primary microglia were pre-treated with GLP at various concentrations for $2 \mathrm{~h}(1 \mathrm{ng} / \mathrm{ml}-1 \mu \mathrm{g} / \mathrm{ml}$ for BV2, $0.3 \mathrm{ng} / \mathrm{ml}-0.1 \mu \mathrm{g} / \mathrm{ml}$ for primary microglia). At the end of pre-treatment, $1 \mu \mathrm{g} / \mathrm{ml}$ LPS (055:B5, Sigma) or $10 \mu \mathrm{M} \mathrm{A} \beta_{42}$ oligomer was added for further $24 \mathrm{~h}$.

\section{Quantitative real-time reverse transcription polymerase chain reaction (qRT-PCR)}

To analysis the mRNA expression, BV2 cells were seeded into 96-well plates and primary microglia into 12-well plates at appropriate densities. After the cell treatment, total RNA was extracted using the TRI Reagent $^{\oplus}$ (Sigma) according to the manufacturer's instructions. RNA purity and integrity were assessed with NanoDrop 1000 Spectrophotometer (Thermo Scientific). A two-step first-strand cDNA synthesis reaction was performed using TIANScript M-MLV kit (TIANGEN) following the manufacturer's protocols. Addition of rRNasin $^{\circ}$ (Recombinant rRNasin ${ }^{\circ}$ Ribonuclease Inhibitor, Promega) was used in the synthesis. The expression of mRNAs was determined by quantitative real-time PCR using the $2 \times$ HotStart SYBR Green qRT-PCR Master Mix kit (ExCell). In brief, the reaction consisted of $4 \mu \mathrm{l}$ of pre-diluted cDNA in a total volume of $25 \mu$ supermix containing $0.25 \mu \mathrm{M}$ primers. The reaction parameters were as follows: $95^{\circ} \mathrm{C}$ for $10 \mathrm{~min} ; 95^{\circ} \mathrm{C}$ for $30 \mathrm{~s}, 40$ cycle; $60{ }^{\circ} \mathrm{C}$ for $30 \mathrm{~s} ; 72{ }^{\circ} \mathrm{C}$ for $30 \mathrm{~s}$. An additional cycle was performed for evaluation of primer's dissociation curve: $95{ }^{\circ} \mathrm{C}$ for $1 \mathrm{~min}, 60{ }^{\circ} \mathrm{C}$ for $30 \mathrm{~s}$ and $95{ }^{\circ} \mathrm{C}$ for $30 \mathrm{~s}$. Each cDNA sample was amplified in duplicates. Primer sequences used in the experiments are listed in Table 1.

\section{ELISA determination of IL- 6}

The supernatants from each treatment were collected for ELISA assays. The supernatants were first centrifuged to
Table 1 Primers used for $\mathrm{qPCR}$

\begin{tabular}{|c|c|c|}
\hline ene & Forward & Reverse \\
\hline$-1 \beta$ & GGACCCCAAAAGAT & AAGGTCCACGGGAAAGACAC \\
\hline 0 & C & TTG \\
\hline$S$ & $\mathrm{G}$ & $A C$ \\
\hline g1 & GAACACGGCAGTGGCTTIAAC & TGCTI \\
\hline$F \beta$ & CACTGATACGCCTGAGTG & GTGAGC \\
\hline CP- & ATGCAGGTCCCTGTCATGCTTC & TTCTGATCTCATTTGGTTCCGA \\
\hline $1 \mathrm{q}$ & GGCTGGAGCATCCAGTTTGA & GTCATGGTCAGCACACAGGC \\
\hline
\end{tabular}

remove cellular debris. Concentrations of IL- 6 were determined using mouse-specific pre-coated ELISA kits (DAKEWE Biotech Company) according to the manufacturer's instructions.

\section{Immunocytochemistry}

Cultured mouse microglia were fixed in $4 \%$ paraformaldehyde (PFA) in PBS at room temperature for $15 \mathrm{~min}$. Cells were then permeabilised and blocked non-specific bindings (1\% BSA and $0.1 \%$ Triton X-100 in PBS) for $30 \mathrm{~min}$. At room temperature, primary antibody anti-Iba1 (1:1000, WAKO) was applied for $2 \mathrm{~h}$ followed by secondary antibody Cy3-conjugated anti-rabbit IgG (1:1000) for $1 \mathrm{~h}$. The immunocytochemistry staining images were captured using Olympus IX51 camera with an inverted laser (X-Cite ${ }^{\circ}$ series120) and a $20 \times / 0.45$ Olympus objective.

\section{Scratch wound migration assay and morphological characterisation}

BV2 cells were grown in 48-well plates till 70-80\% confluent. The monolayer of cells was then wounded with a sterile $200-\mu$ pipette tip in a straight line along the diameter of the well and washed three times with sterile PBS. The cells were grown for further $24 \mathrm{~h}$ allowing migration into the open scratched area. Images of cells were captured at 0 and $24 \mathrm{~h}$ after wounding, using a Zeiss A-Plan $5 \times$ objective $(0.12 \mathrm{Ph} 0)$ and the Zeiss Observer Z1 microscope. Only single distinct cell was selected for morphological analysis. Dividing cells and those attached to each other were excluded. The absolute value of distance migrated by cells was quantified as the change in the perpendicular distance between the edge of the gap after $24 \mathrm{~h}$. The value was then normalised to the $0 \mathrm{~h}$ starting measurement which represents "migration" ( $\left.\frac{\text { Migration= }=\text { Distance }_{24} \text { hours }- \text { Distance }_{0} \text { hour }}{\text { Distance }_{0} \text { hour }}\right)$. We used the Fiji ImageJ software (Version 2.0.0) to quantitatively characterise the morphology using the following parameters: cell area, perimeter, Feret's diameter (the longest distance between any two points along the selection boundary) and circularity $\left(4 \pi \frac{\text { Area }}{\text { Perimeter }^{2}}\right)$. 


\section{Phagocytosis assay}

BV2 and primary microglia were plated into 24-well plates at appropriate densities to ensure the cells confluent to approximately 30,000 per well at the time of assay. Pre-treatment of GLP was carried out $2 \mathrm{~h}$ after plating and followed by stimulation with LPS or $A \beta_{42}$. Phagocytosis assay were performed based on the protocol previously described [26]. Cell medium were changed to DMEM alone and allowed incubation for $30 \mathrm{~min}$ inside the $37{ }^{\circ} \mathrm{C}$ cell culture incubator. After this, the media were replaced by DMEM supplemented with $5 \%$ FBS under various treatment conditions for GLP and stimuli. The fluorescent latex beads $(1 \mu \mathrm{M}, \mathrm{L} 2778$ Sigma) were pre-opsonised in 50\% FBS and PBS. The pre-opsonised beads were loaded to the cells at concentrations of 50 beads per BV2 cell and 100 beads per primary microglia and incubated at $37{ }^{\circ} \mathrm{C}$ for 2 and $3 \mathrm{~h}$, respectively. Negative controls were carried out with pre-treatment of Cytochalasin $\mathrm{D}$ for $30 \mathrm{~min}$ at $37{ }^{\circ} \mathrm{C}$ in order to prevent phagocytosis. At the end of incubation, the remaining beads were gently washed off the cells and fixed by $4 \%$ PFA at room temperature. Cells were then stained with DAPI (4',6-diamidino-2-phenylindole) at room temperature for $15 \mathrm{~min}$, and images were captured under Zeiss Observer Z1 inverted microscope. For each well, DAPI, Cy3 and brightfield images were collected $(N=15-30)$ and analysis was done by Fiji ImageJ software (Version 2.0.0).

\section{Zebrafish and embryo maintenance}

Zebrafish and embryo were raised in egg water in a 14-h light and 10-h dark cycle at $28.5^{\circ} \mathrm{C}$ as described [27]. To inhibit pigmentation, $0.003 \%$ PTU was added to each samples at $24 \mathrm{~h}$ postfertilisation (hpf). The double transgenic zebrafish line $\operatorname{Tg}($ ApoE:GFP, Huc:mcherry) was as previously described [28]. The zebrafish embryonic growth was first monitored in the presence of $1 \mu \mathrm{g} / \mathrm{ml}$ GLP from $12 \mathrm{hpf}$ to 5 days postfertilisation (dpf). No developmental defects were observed (Fig. 4a-c). Subsequent experiments were performed pre-treating larva with GLP from $4 \mathrm{dpf}$ for $24 \mathrm{~h}$.

\section{In vivo time-lapse confocal imaging}

$1.5 \%$ low melting point agarose (Sigma) was prepared to fix the 5-dpf larvae alive without anaesthetics. A dorsal view of the optic tectum is placed. Living imagines were carried out in $1 \mu \mathrm{m} /$ optical section $(40-65 \mu \mathrm{m}$ in depth) in a 5-min interval using Olympus FV1000 upright confocal microscope (473 nm, $543 \mathrm{~nm}$; Japan) with a Zeiss $40 \times$ NA 0.80 water immersion.

\section{Image analysis}

Resting and activated state morphology dynamic was analysed as previously described [28, 29]. The cell size, deformation speed and tip number of microglia were measured by the Fiji ImageJ (version 2.0.0).

\section{Cell viability assay}

The proliferative potential of GLP was examined in the presence or absence of LPS. The BV2 cell proliferation was tested using the CellTiter-Glo luminescent cell viability assay (Promega) following the manufacturer's instructions.

\section{Statistics}

Statistical analysis was performed using GraphPad Prism 6 software (Graphpad Software, La Jolla, CA, USA). Results were analysed by unpaired two-tailed Student's $t$ test to determine the significance of the treatment sets. For comparisons between multiple groups, one-way ANOVA analysis with Tukey's multiple comparison test was performed. All data were presented as mean \pm SEM. $p<0.05$ is considered to have significant difference.

\section{Results \\ GLP attenuates LPS- or A $\beta$-induced inflammatory response in microglia}

In the previous report, GLP by an alternative extraction technique with different purity was shown to inhibit microglial activation [30]. In order to verify the integrity of the GLP used in the present study, we first examined the cytotoxicity and proliferative potential of GLP for $24 \mathrm{~h}$ (Additional file 1: Figure S1A). Further long-term (48, 72 and $96 \mathrm{~h}$ ) incubations confirmed GLP did not affect cell growth (Additional file 1: Figure S1B). We then investigated the effect of GLP on the LPS-induced microglial activation (Fig. 1a-e). BV2 cells were pre-treated with GLP for $2 \mathrm{~h}$ followed by LPS stimulation. We showed that GLP inhibited LPS-induced proinflammatory cytokines IL-1 $\beta$, IL- 6 and inducible nitric oxide synthase (iNOS) expressions in a concentrationdependent manner (Fig. 1a-c). The LPS-induced IL-1 $\beta$ and IL- 6 expressions were effectively reduced by GLP at 0.1 and $1 \mu \mathrm{g} / \mathrm{ml}$, and iNOS expression down-regulated at $1 \mu \mathrm{g} / \mathrm{ml}$. At lower concentrations $(0.01$ and $0.1 \mu \mathrm{g} / \mathrm{ml})$, the effect of GLP on iNOS was not statistically significant. However, a concentration-dependent trend was observed. In addition, GLP up-regulated the anti-inflammatory cytokine TGF $\beta$ expression in the presence of LPS. It also revealed a tendency to increase Arg1 expression in the absence of LPS (Fig. 1d, e). In AD, the microglia-mediated neuroinflammation is stimulated by $A \beta$. Therefore, in this study, we used the soluble form of oligomeric $A \beta_{42}$ and examined the role of GLP in primary mouse microglia (Fig. 1g-j, l). The results showed that GLP significantly inhibited the $A \beta_{42}$-induced pro-inflammatory cytokines IL-1 1 , IL- 6 and iNOS to approximate basal levels. In addition, GLP exhibited tendencies to promote 


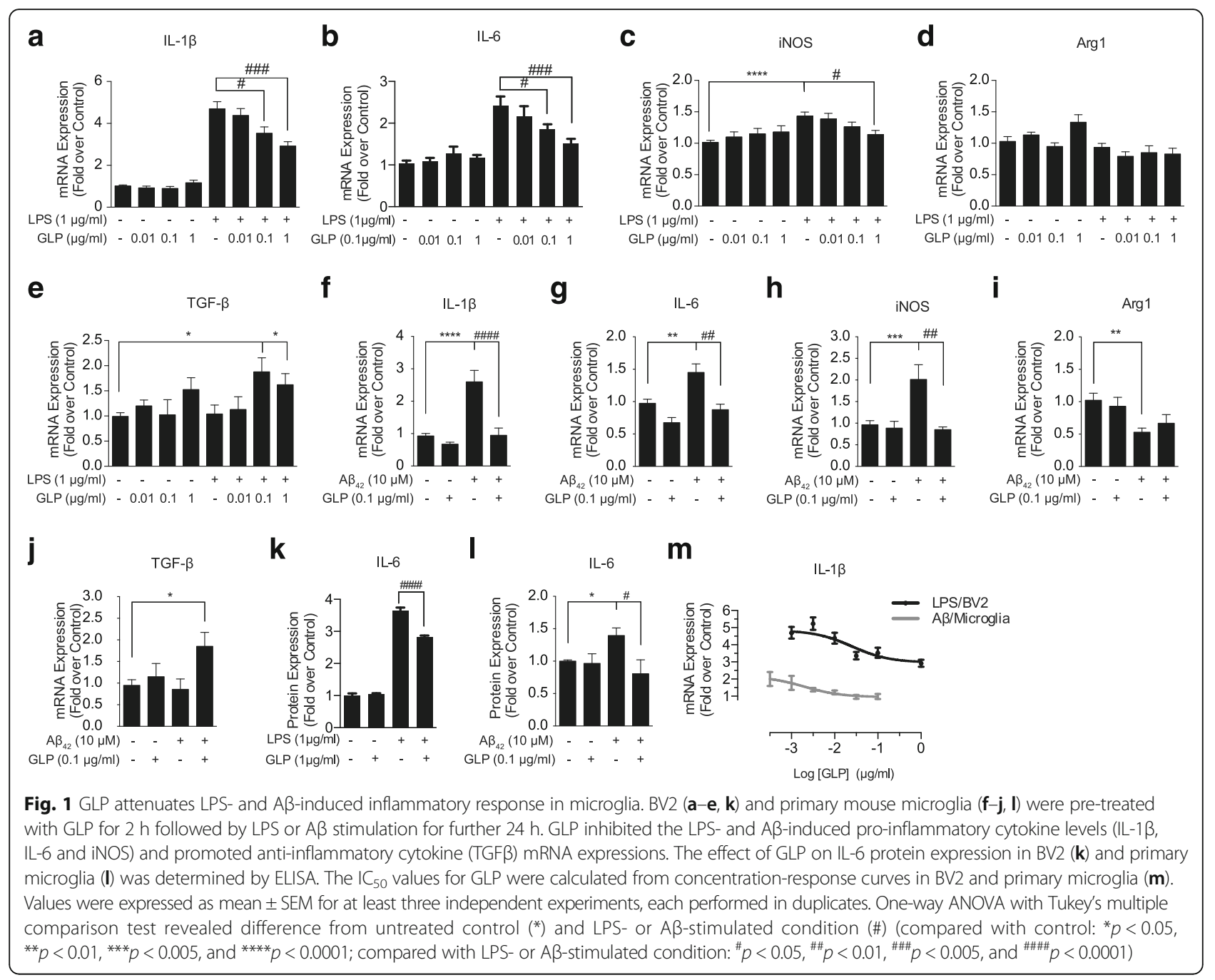

anti-inflammatory cytokine expressions (Fig. 1i, j). Under $\mathrm{A} \beta_{42}$ activation, Arg1 expression was significantly reduced. It seemed that pre-treatment of GLP might potentially rescue its expression, but the effect was not significant. On the other hand, GLP promoted TGF $\beta$ expression in $\mathrm{A} \beta_{42}$-activated cells. We then confirmed these findings at protein levels by measuring the IL- 6 protein expressions using ELISA (Fig. $1 \mathrm{k}, \mathrm{l}$ ). The $\mathrm{IC}_{50}$ values of GLP in both BV2 and primary microglia were analysed from concentration-response curves, the IL- $1 \beta$ expressions were determined as representatives. These values were calculated using GraphPad Prism software. The $\mathrm{IC}_{50}$ values were $25 \mathrm{ng} / \mathrm{ml}\left(\operatorname{LogIC}{ }_{50}=-1.598\right)$ and $2 \mathrm{ng} / \mathrm{ml}$ $\left(\operatorname{LogIC} C_{50}=-2.704\right)$ for BV2 and primary microglia, respectively (Fig. 1m). Overall, GLP attenuated BV2 and primary microglial activation by reducing the proinflammatory cytokine expression and promoted the antiinflammatory cytokine levels.
GLP modulates LPS- and A $\beta$-induced microglial migration and morphological changes

The expression of MCP-1 is associated with neuroinflammation and cell motility. We showed increased levels of MCP-1 expressions in BV2 and primary microglia as the results of LPS and A $\beta$ activations, respectively. GLP inhibited such increase of MCP-1 expression (Fig. 2a, b). The reduction in the MCP-1 expression thus might correlate with the attenuated microglial inflammation states and down-regulation of pro-inflammatory cytokine levels. We examined whether the decrease in MCP-1 level leads to changes in microglial morphology and migration (Fig. 2c-j). Our results revealed the LPS-stimulated BV2 migration towards the scratched open area was suppressed by GLP treatment (Fig. 2c, d). Further investigation in BV2 cells observed two major morphological phenotypes, the short-round morphology and the stretched and elongated morphology, 


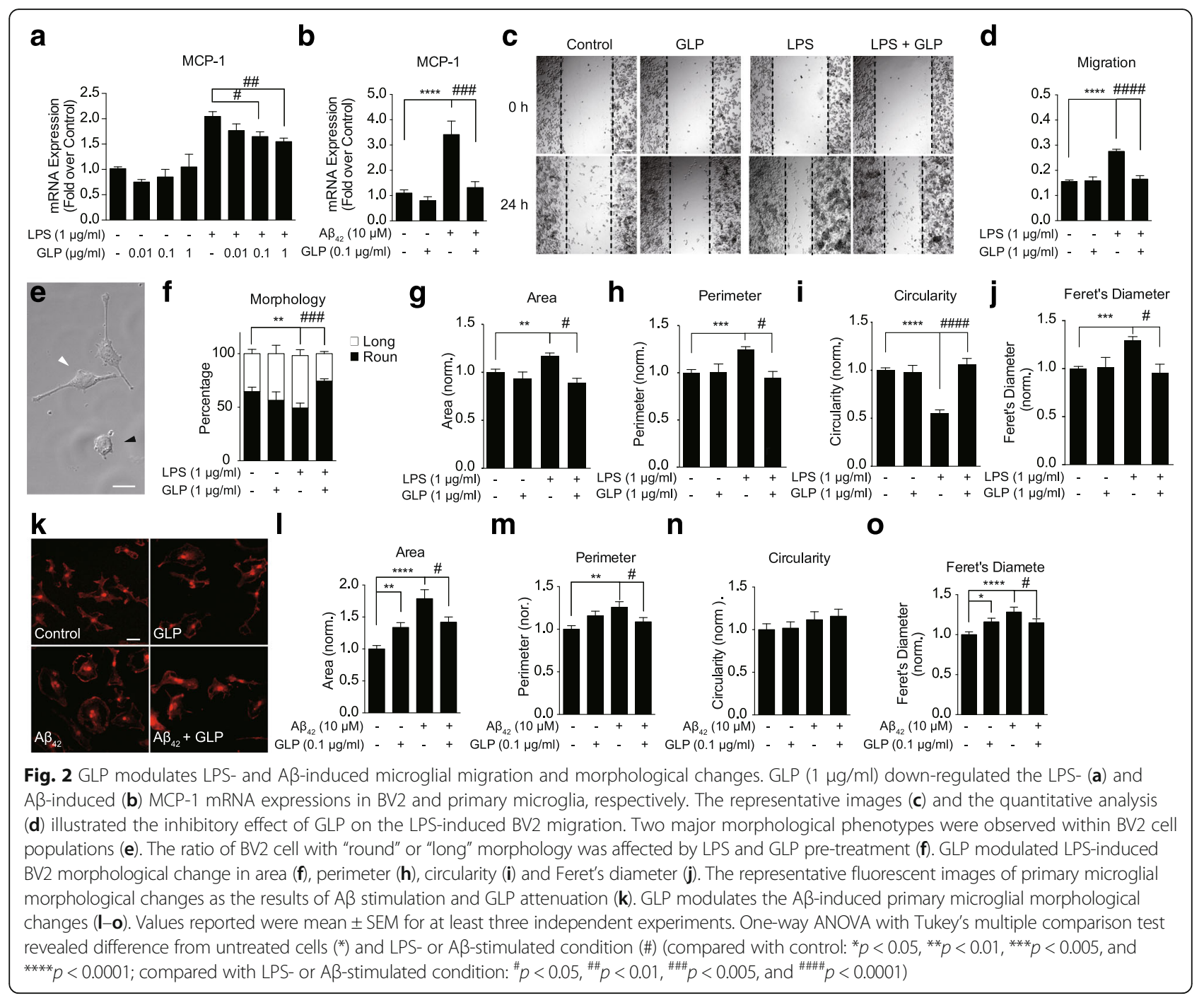

here designated as "round" and "long" (Fig. 2e). The untreated BV2 existed mostly round, and under LPS activation, the number of long cells increased significantly. However, pre-treatment with GLP restored the morphologies to round (Fig. 2f). We then carried out more detailed morphological characterisation (Fig. $2 g-j$ ). The results revealed that LPS induced increases in cell area, perimeter and Feret's diameter and a decrease in circularity. These morphological modulations associated with the LPS stimulation were inhibited by GLP pretreatment. These findings were confirmed in primary microglia (Fig. $2 \mathrm{k}-\mathrm{o}$ ). Activation by $\mathrm{A} \beta$ caused microglial morphological changes from ramified to amoeboid with increases in soma sizes. In the presence of GLP, significant inhibitions in the cell area, perimeter and Feret's diameter measures were detected indicating the modulations of microglial morphologies towards the unstimulated state. It was not clear of the exact reason that GLP treatment alone induced slight increase in the cell area, perimeter and Feret's diameter. Since no change in the pro-inflammatory cytokine levels were detected, it suggested such changes were unlikely due to inflammatory responses.

\section{GLP inhibited LPS- and A $\beta$-induced phagocytosis in microglia}

Further, we examined whether, under the same conditions for the inhibited pro-inflammatory cytokines and MCP-1 expressions, GLP modulated microglial phagocytosis. The experiment was conducted using $1-\mu \mathrm{m}$ fluorescent latex beads in order to induce detectable engulfment by microglia. We demonstrated that in both BV2 and primary microglia, LPS and A $\beta$ activation led to increased number of phagocytic cells, whilst pre-treatment with GLP (1 and $0.1 \mu \mathrm{g} / \mathrm{ml}$ for BV2 and primary microglia, respectively) significantly reduced the phagocytosis events (Fig. 3c, f). We also observed a tendency of changes in the phagocytic capacity in both BV2 

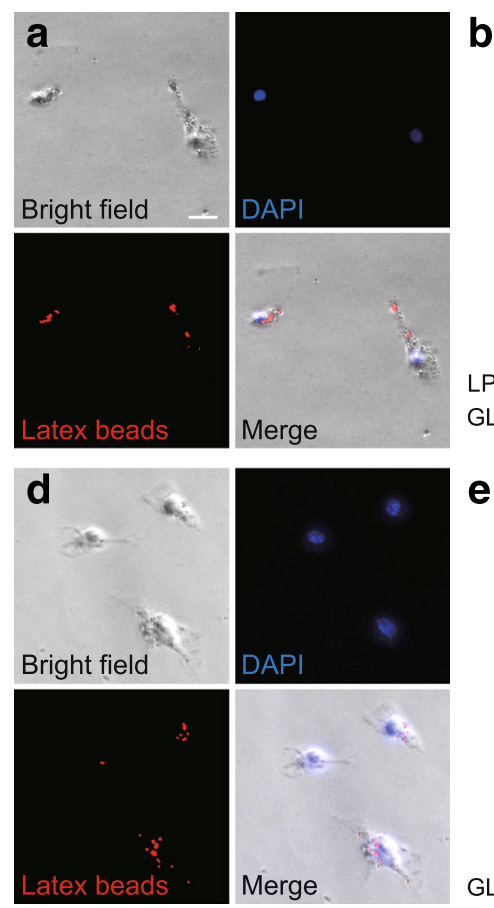

g

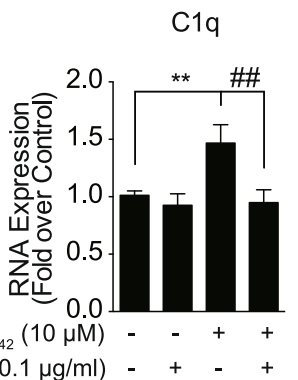

b Phagocytosis Capacity

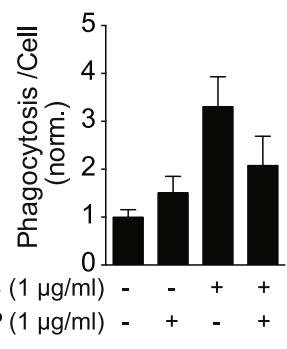

e Phagocytosis Capacity

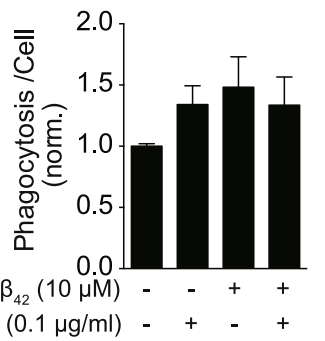

\section{C}

Phagocytic Cells

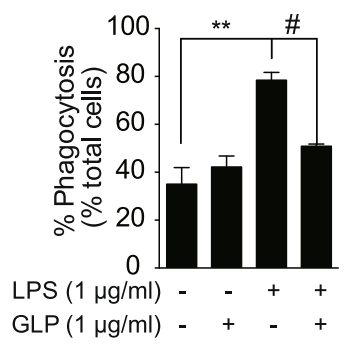

f

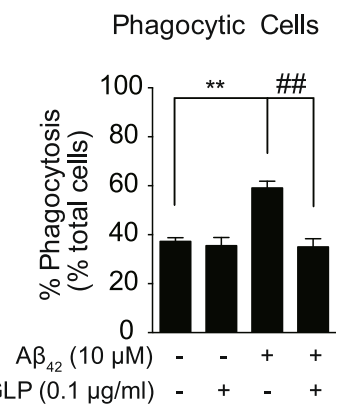

Fig. 3 GLP inhibited LPS- and A -induced phagocytosis in microglia. The effect of GLP on the LPS- $(\mathbf{a}-\mathbf{c})$ and A -induced (d-f) phagocytosis in BV2 (a) and primary mouse microglia (d), respectively. The phagocytosis capacity was expressed as the ratio of total areas of fluorescent signals to the total numbers of phagocytic cells $(\mathbf{b}, \mathbf{e})$. GLP reduced the proportions of phagocytic cell resulted from LPS and A $\beta$ activation $(\mathbf{c}, \mathbf{f})$. The complement C1q mRNA expression was quantified in primary microglia and GLP inhibited the Aß-promoted C1q expression (g). Values expressed are mean \pm SEM for at least three independent experiments. Images of phagocytosis were captured from 16-30 fields per well of cells. Statistical analysis was performed using one-way ANOVA with Tukey's multiple comparison test, differences from untreated cells $\left(^{*}\right)$ and LPS- or Aß-stimulated condition (\#) were revealed (compared with control: ${ }^{* *} p<0.01$; compared with LPS- or A -stimulated condition: ${ }^{\#} p<0.05$ and ${ }^{\# \#} p<0.01$ )

and primary microglia (Fig. 3b, e), but the differences were not statistically significant. Cytochalasin D pretreatment were used as the negative control experiment to completely prevent phagocytosis. Beads attached to the cell surfaces were washed off at the end the phagocytosis assay, and no fluorescent signal was detected from Cytochalasin D pre-treated cells (data not shown). Collectively, our results revealed GLP inhibited the LPSand $\mathrm{A} \beta$-promoted phagocytosis at 1 and $0.1 \mu \mathrm{g} / \mathrm{ml}$ concentrations, respectively. Under these conditions, the reductions in IL-1 $\beta$, IL-6 and iNOS expressions were previously observed. In addition, microglial complements are extensively related to phagocytosis and $\mathrm{A} \beta$ clearance [31]. In particular, $\mathrm{C} 1 \mathrm{q}$ expression was reported to associate to $A \beta$-induced synaptic loss [31]. We thus examined the expression of complement $\mathrm{C} 1 \mathrm{q}$ expression. The results showed an elevated level of $\mathrm{C} 1 \mathrm{q}$ expression by $A \beta$ stimulation and reduction by GLP (Fig. 3g). We did not detect significant $\mathrm{C} 1 \mathrm{q}$ expression in LPS-stimulated BV2 cells. Previous studies reported that siglec receptors bound to a wide range of sialyloligosaccharides are important regulators of innate immunity [32]. SiglecE and $\mathrm{H}$ expressed in mouse microglia were demonstrated to modulate phagocytosis [33-35]. Therefore, we aimed to examine whether GLP modulated phagocytosis in BV2 and primary microglia 
was through siglec receptors. However, we did not detect expressions of siglecE or $\mathrm{H}$ in BV2 cells, which implies that the GLP modulation of phagocytosis might be independent of the siglec receptor mechanism.

\section{GLP modulates microglial morphology and phagocytosis in vivo}

To confirm the results in vivo, further investigation in the zebrafish brain was conducted in order to determine the role of GLP in microglial behavioural modulations including morphology and phagocytosis changes. A double transgenic lines Tg(Apo-E:eGFP, HuC:mCherry) [29] were used, with Apo-E:eGFP visualising microglia in green and Huc:mcherry labelling neuron in red. The time-lapse images were captured at 5-min intervals for $60 \mathrm{~min}$ as previously described [28]. The zebrafish embryonic growth was monitored in the presence of $1 \mu \mathrm{g} / \mathrm{ml}$ GLP from $12 \mathrm{hpf}$ to $5 \mathrm{dpf}$. No developmental defects were observed (Fig. $4 \mathrm{a}-\mathrm{c}$ ). There are resting and activated microglia in the optic tectum as classified by different reactions in this region [36]. We first analysed the resting microglial morphological dynamics (Fig. $4 \mathrm{~d}-\mathrm{h}$ ). Based on previous literature descriptions [37], resting microglia in vivo have "immotile" cell body and many relatively "motile" processes constantly branching out to scan the microenvironment. Our data showed that GLP resulted in a slight decrease in the cell sizes, but the changes in the numbers of branching tips were not significant. The microglial deformation speed, which is defined by difference in cell area between two sequential processes projections, was not affected. For activated microglia in vivo, the cell bodies move fast in the tissue [37]. We analysed the effect of GLP on the activated microglial cell size, tip number and phagocytic properties (Fig. $4 \mathrm{i}-\mathrm{m}$ ). The results showed that GLP decreased activated microglial cell size and phagocytic probability (Fig. $4 \mathrm{~m}, \mathrm{j}$ ). However, the effect of GLP on activated microglial tip number and phagocytosis time-length was not significant (Fig. 4l, k).

\section{Discussion}

In the present study, we aimed to investigate the effect of GLP on microglia-mediated neuroinflammation. We first showed that GLP inhibited the LPS-induced pro-inflammatory cytokine expressions in BV2 cell lines. The expressions of IL-1 $\beta$, IL- 6 and iNOS are associated with neurodegenerative diseases. The IL- $1 \beta$ is a potent neuroimmune mediator that takes effect on various cell types including neurons and microglia [38]; iNOS expression is elevated in activated microglia with its synthetic product nitric oxide being one of the major causes of neurodegenerative diseases [39]; and the expression of IL-6 is also strongly linked to AD as an inflammatory mediator $[40,41]$. These results thus provide implications that GLP might exhibit neuroinflammation modulatory effects in neurodegenerative diseases such as AD. Therefore, we confirmed this finding in primary microglia in the presence and absence of $A \beta$ activation, and the results were consistent with the responses in BV2 cell. The analysis of $\mathrm{IC}_{50}$ values was based on the expression of IL-1 $\beta$ as a representative. The results revealed that GLP seemed to be a more potent inhibitor to $\mathrm{A} \beta$ activations in primary microglia compared to BV2 cells when stimulated by LPS. The differences in the $\mathrm{IC}_{50}$ values may be attributed to dissimilarities between a cell line and primary cultured microglia, although the different inflammatory stimuli (A $\beta$ and LPS) should also be taken into account. Nevertheless, GLP inhibition of these $\mathrm{A} \beta$-induced inflammatory mediators implies that it might be a potent modulator for AD-related neuroinflammation. In addition, we detected that GLP promoted a significant rise in the anti-inflammatory cytokine TGF $\beta$ expression in both BV2 and primary microglia. TGF $\beta$ plays crucial role in the inhibition of microglia and macrophage classic activations, the expression of which also enhances the IL-4-induced microglial alternative activation [42]. In combination with previous literature evidence which demonstrated a TGF $\beta 1$-dependent clearance of $A \beta$ in microglial cultures [43], our results thus imply that GLP might ameliorate AD pathology. Meanwhile, we also analysed the expression of another antiinflammatory cytokine arginase-1 (Arg1); we did not detect changes in Arg1 expression. Recently, GLP has been demonstrated to promote NPC proliferation and improve cognitive functions in APP/PS1 transgenic mice, with a significant effect on the $A \beta$ clearance [44]. Therefore, GLP becomes a prominent "dual functional" natural product in targeting $\mathrm{AD}$, possibly via simultaneous actions on both the anti-neuroinflammation and the neurogenesis mechanisms.

As the results of microglial activation, cells display remarkable characteristics in behavioural changes, such as morphology, migration and phagocytosis. Increasing amounts of researches have now focused on to elucidate both the function and morphology of microglia in the healthy and injured brains [45-47]. A recent example in the analysis of microglial morphological and phagocytic activity changes revealed that microglia being the "first responder" after ischemic stroke and subsequent reperfusion process [48]. We observed the LPS-induced BV2 migration towards the open scratched area was significantly blocked by $1 \mu \mathrm{g} / \mathrm{ml}$ GLP. At the same concentration, GLP also showed remarkable inhibitions to the LPS-induced pro-inflammatory cytokine and MCP-1 expressions. In addition, we also recorded during LPS activation BV2 cells elongated and extended from the mostly short and compact morphology to a long shape. This finding coincides with a previous report in which BV2 cells were incubated in the conditioned medium 
a
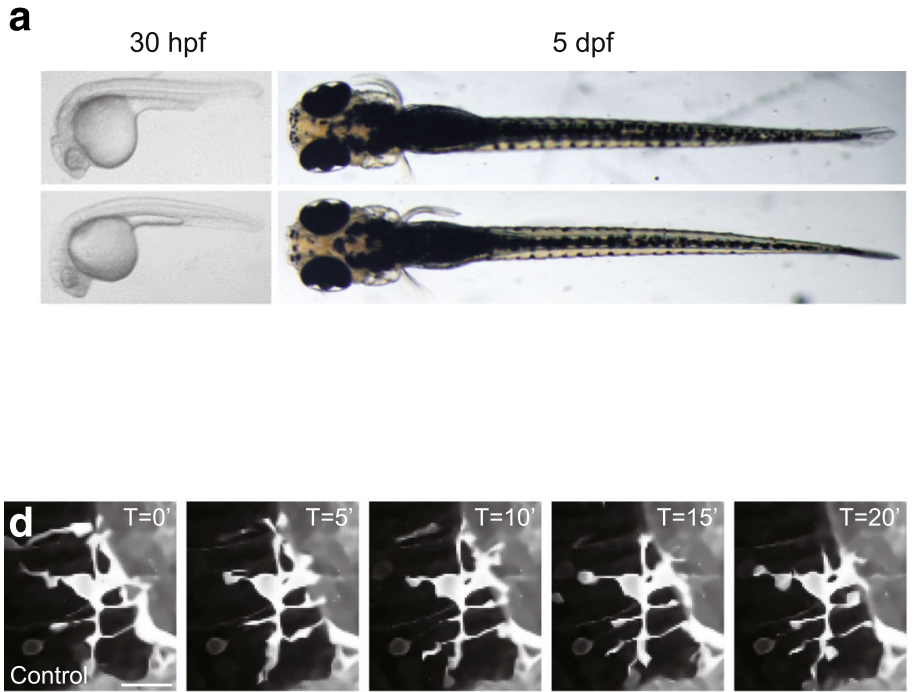

e
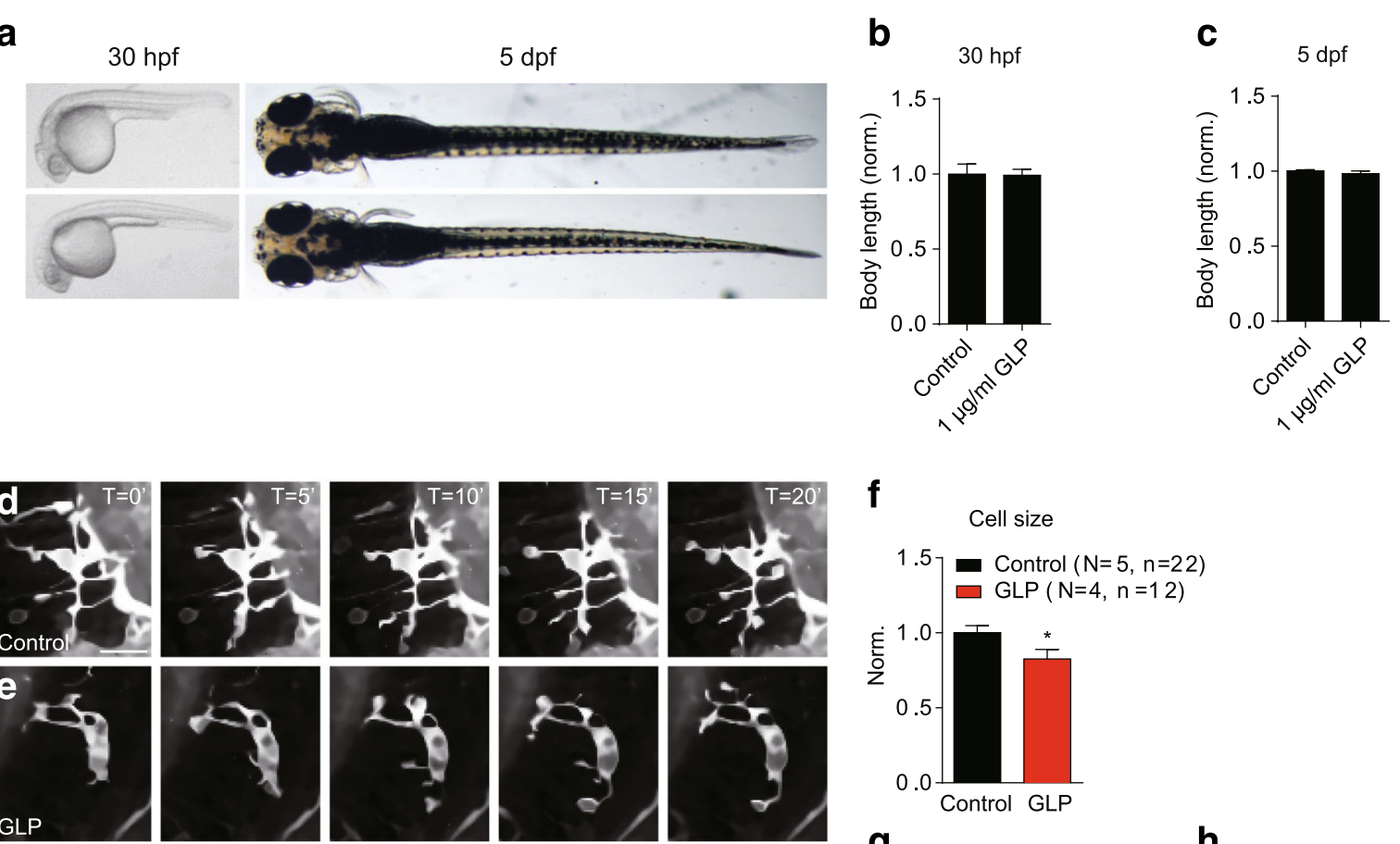

f
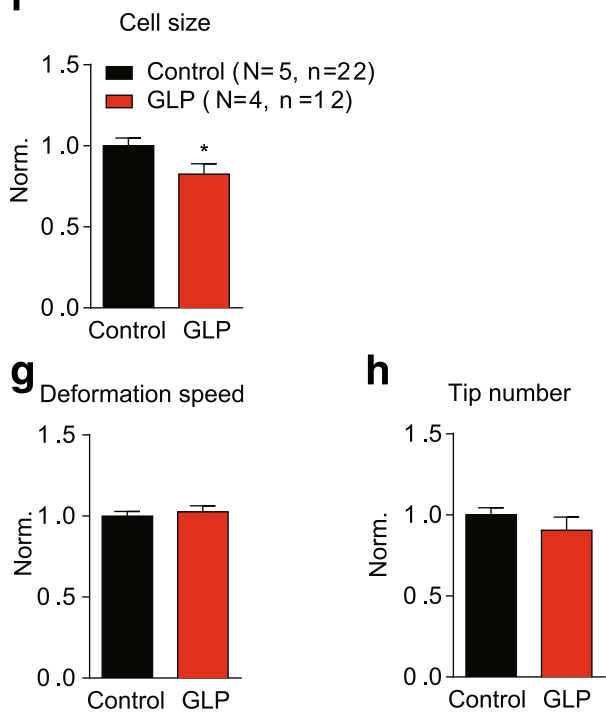

i
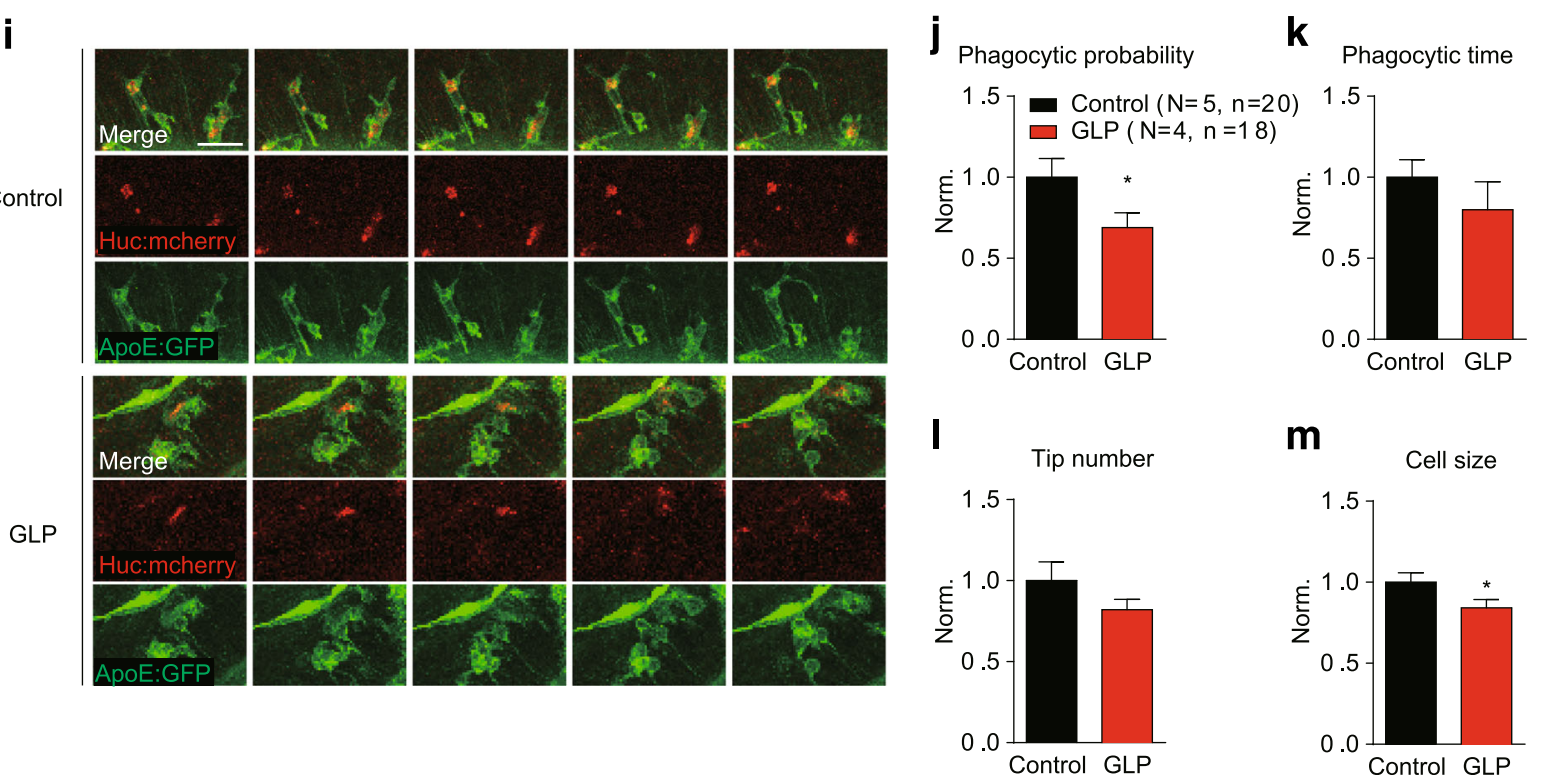

Fig. 4 (See legend on next page.) 
(See figure on previous page.)

Fig. 4 GLP modulates microglial morphology and phagocytosis in vivo. Zebrafish embryo (30 hpf) grown in GLP revealed no developmental defect (a). Continued treatment with GLP during the embryonic developmental stage did not affect the larva body lengths (b, c). Dorsal view of the optic tectum in a 5-dpf Tg(Apo-E:eGFP, HuC:mCherry) zebrafish larvae. Time-lapse images of the dynamics of resting microglia pre-treated with (e) or without (d) $1 \mu \mathrm{g} / \mathrm{ml}$ GLP. The time scales were in minutes. $\mathbf{f}-\mathbf{g}$ The effects of GLP on resting microglial cell sizes, deformation speed and tip numbers. $\mathbf{h}$ Time-lapse images showing the phagocytic process of microglia Tg(Apo-E:eGFP, HuC:mCherry) zebrafish larvae at $5 \mathrm{dpf}$. The effect of $1 \mathrm{\mu g} / \mathrm{ml}$ GLP on activated microglial phagocytosis $(\mathbf{j}, \mathbf{k})$ and morphology $(\mathbf{I}, \mathbf{m})$. Data normalised to control. $N$ stands for numbers of zebrafish and $n$ for the number of cells. Statistical analysis was performed using unpaired two-tailed Student's $t$ test. Values expressed are mean \pm SEM. $\left({ }^{*} p<0.05\right)$

from spinal cord injury for 3-48 h [49]. We provided quantitative descriptions for changes in morphology as decreased cell circularity with increased Feret's diameter and confirmed that the changes ultimately led to the augmented cell area and perimeter. On the other hand, the quantitative descriptions for primary microglial morphological changes did not entirely follow the observations for BV2. No significant difference was detected in cell circularity under $A \beta$ stimulation, even though there seemed to be an increasing trend. This might be due to the more "irregular" shape of primary microglia. Despite all, increased Feret's diameter was recorded. As the results of morphology changes, primary microglial cell area and perimeter were remarkably enlarged, which is consistent with BV2 cells. The variations in cell area and perimeter thus seem to be the distinctive features following BV2 and primary microglial activation. Further investigation showed that the LPS- and A $\beta$-induced morphological changes were almost completely reversed by $1 \mu \mathrm{g} / \mathrm{ml}$ of GLP. In addition, we also studied the effect of GLP on microglial phagocytic behaviour using $1-\mu \mathrm{m}$ latex beads, since the process of phagocytosis engulfs targets not less than $1 \mu \mathrm{m}$. Stimulations with LPS or soluble $A \beta$ oligomer may conceivably mimic the early microglial phagoptosis events. As expected, GLP treatment reduced the LPS- and A $\beta$-promoted phagocytosis. Our results therefore illustrated GLP modulations on microglial behaviour were associated to MCP-1 expressions. We further extended the investigations of GLP modulations of microglial behaviour in vivo. The zebrafish model used was a double transgenic line, with ApoE:eGFP-labelled microglia in green and HuC:m Cherry-labelled neurones in red. Transgenic lines of both labelling were well established $[50,51]$. It should be noted that Apo-E was previously described as a zebrafish microglial marker [52, 53]; the $\operatorname{Tg}(A p o-E: e G F P)$ line were then raised in order to reveal zebrafish microglia in green colour [50]. The specificity of this labelling was proved with pU1 morpholino injection, which led to a complete disappearance of Apo-E-positive cells thus confirming the myeloid origin of these labelled cells [50]. In the zebrafish, the cell size, tip numbers and deformation speed are the characteristic features defining resting microglial morphology. GLP reduced the resting microglial cell sizes in vivo, with little impact on the tip numbers and deformation speeds. In BV2, the unstimulated cell morphologies remained unaltered in the presence of GLP. Meanwhile, in the primary microglia, GLP resulted in a slight increase in cell area. Since the pro-inflammatory cytokine levels remained unchanged, it is unlikely that the increase in cell area was resulted from microglial activation. The results of GLP inhibition of activated microglial cell size and phagocytosis in zebrafish were consistent with the findings in LPS- and A $\beta$-stimulated BV2 and primary microglia.

One other distinguished observation in this study is the complement $\mathrm{C} 1 \mathrm{q}$ correlation with oligomeric $\mathrm{A} \beta$ stimulation in microglia. This finding is supported by earlier researches [31]. Previously, Stevens et al. [31] demonstrated that microglia is the main source of complement $\mathrm{C} 1 \mathrm{q}$ and the expressions of which are specific to the hippocampus and frontal cortex regions in the brain [54]. C1q expression is an essential requirement for the oligomeric $A \beta$-induced synaptic loss in vivo [55-57]. Deficit in C1q results into an increased number of synapses and provides a neuroprotective function $[31,55]$. Our results imply that GLP displayed neuroprotective effect against $A \beta$ oligomers as the treatment with GLP significantly reduced the C1q expression. Furthermore, the neuroprotective effect of GLP might be also achieved through the inhibition of inflammation-induced phagocytosis. Microglial phagocytosis can be considered beneficial under various circumstances. The removal of dead neurones and debris or even excessive live neurones and precursors during adult neurogenesis maintains a homeostatic environment $[34,35]$. However, in situations where phagocytosis is stimulated via inflammation, the consequence of which can be detrimental. Although at early-stage phagocytosis may reduce inflammation, excessive removal of pathogens, dead or infected neurones and synapses may lead to phagoptosis of live neurones and synapses [58-60]. Phagocytosis and aberrant phagoptosis are in fact associated with many neurodegenerative diseases such as AD, Parkinson's disease and frontotemporal degenerations [59, 61, 62]. Mutations in various phagocytosis genes (TREM2, complement receptor 1, CD33, APOE, etc.) were also implicated as risk factors for neurodegenerative diseases 
$[61,63,64]$. Our in vitro study thus provides implication that GLP may act at early stage of the disease to attenuate inflammation and maintain a controlled phagocytosis event.

\section{Conclusions}

In conclusion, our study provides an insight into the regulatory roles of GLP in LPS- and A $\beta$-induced microglial behaviour and pro-inflammatory responses. The study stresses the significance of investigation in microglial behavioural response to neuroinflammation. A particular importance is the use of $A \beta$ in order to mimic microgliamediated neuroinflammation in AD. The results indirectly serve an indication that GLP exhibits a neuroprotective function in the treatment of $\mathrm{AD}$. In conjunction with the neurogenesis effect [44], GLP represents a dual functional cocktail-like natural product, which bares a great potential in the early prevention and treatment of AD.

\section{Additional file}

\begin{abstract}
Additional file 1: Figure S1. GLP exhibited no cytotoxicity and proliferative effect to BV2 cells. (A) GLP effect on BV2 cell viability was examined for $24 \mathrm{~h}$ in the presence and absence of LPS stimulation. No cytotoxicity was detected. GLP long-term effect on cell growth was investigated for 48, 72 and $96 \mathrm{~h}$. Cell growth was estimated by total cell count (B) and CellTiter-Glo assay (C). Cells were incubated in normal DMEM culture medium with 10\% FBS supplement. Both 1 and $0.01 \mu \mathrm{g} / \mathrm{ml}$ showed no effect on cell growth compared to untreated control. Cells grown in FBS-depleted medium (2\% FBS) showed little cell growth, whereas in the FBS-enriched medium (30\% FBS), the cell growth exceeds normal cultured medium. Figure S2. Confirmation on the integrity of prepared $A \beta$ oligomer. Four microliters of oligomers or fibril were loaded to the nitrocellulose membrane. Dot blot was performed and the oligomer-(A11) and Fibril-specific (ab126468) antibodies were used. In the prepared oligomer (left lane), little fibril fractions were detected, whilst in the prepared $A \beta$ fibril (right lane), certain levels of oligomers were also detected. Staining of 6 E10 revealed the total $A \beta$ content. (PDF $207 \mathrm{~kb}$ )
\end{abstract}

\section{Abbreviations \\ AD: Alzheimer's disease; Arg1: Arginase 1; Aß42: Amyloid beta 42 ; CNS: Central nervous system; DMEM: Dubelcco's Minimal Essential Medium; DMSO: Dimethyl sulfoxide; dpf: Day postfertilisation; E. coli: Escherichia Coli; ELISA: Enzyme-linked immunosorbent assay; FBS: Fetal bovine serum; GLP: Ganoderma lucidum polysaccharides; HFIP: Hexafluoroisopropanol; hpf: Hour postfertilisation; HPGPC: High-performance gel permeation chromatography; IL-1 ß: Interleukin-1 beta; IL-6: Interleukin-6; LB: Luria Bertani; LPS: Lipopolysaccharides; MCP-1: Monocyte chemoattractant protein; NPC: Neural progenitor cell; PBS: Phosphate-buffered saline; qPCR: Quantitative polymerase chain reaction; Tg: Transgenic; TGF $\beta$ : Transforming growth factor $\beta$; TLR: Toll-like receptor}

\section{Acknowledgements}

We thank Dr. Qian Hu for optimising the image analysis method and for our in vivo time-lapse imaging experiments on Olympus FV1000, Jerome Boulanger for the ndsafir software, and Dr. Jiulin Du lab for providing all the zebrafish line.

\section{Funding}

This research was supported by the Ministry of Science and Technology (2015CB964502) and Shanghai Municipal Commission for Science and Technology (15JC1400202, 14DZ1900402).

\section{Availability of data and materials}

The datasets during and/or analysed during the current study are available from the corresponding author on reasonable request.

\section{Authors' contributions}

GP substantially controlled the study conception and design, interpretation of the data, and critical revision of the manuscripts for important intellectual content. QC performed all the in vitro assays and data analysis. YL performed the in vivo zebrafish experiments and data analysis. QC contributed to the manuscript preparation. All the authors contributed to the manuscript revision and read and approved the final article.

\section{Competing interests}

The authors declare that they have no competing interests.

\section{Publisher's Note}

Springer Nature remains neutral with regard to jurisdictional claims in published maps and institutional affiliations.

\section{Author details}

${ }^{1}$ State Key Laboratory of Cell Biology, Institute of Biochemistry and Cell Biology, Shanghai Institutes for Biological Sciences, Chinese Academy of Sciences, 320 Yueyang Road, Shanghai 200031, China. ${ }^{2}$ Graduate School, University of Chinese Academy of Sciences, Chinese Academy of Sciences, 320 Yueyang Road, Shanghai 200031, China. ${ }^{3}$ School of Life Science and Technology, and the Collaborative Innovation Center for Brain Science,

Tongji University, Shanghai 200092, China.

Received: 9 October 2016 Accepted: 13 March 2017

Published online: 24 March 2017

\section{References}

1. Lin Z-B. Cellular and molecular mechanisms of immuno-modulation by Ganoderma lucidum. J Pharmacol Sci. 2005;99:144-53. Japan.

2. Sliva D. Cellular and physiological effects of Ganoderma lucidum (Reishi). Mini Rev Med Chem. 2004:4:873-9. Netherlands.

3. Wubshet SG, Johansen KT, Nyberg NT, Jaroszewski JW. Direct (13)C NMR detection in HPLC hyphenation mode: analysis of Ganoderma lucidum terpenoids. J Nat Prod. 2012;75:876-82. United States.

4. Pan K, Jiang Q, Liu G, Miao X, Zhong D. Optimization extraction of Ganoderma lucidum polysaccharides and its immunity and antioxidant activities. Int J Biol Macromol. 2013;55:301-6. Netherlands.

5. Huang S-Q, Li J-W, Wang Z, Pan H-X, Chen J-X, Ning Z-X. Optimization of alkaline extraction of polysaccharides from Ganoderma lucidum and their effect on immune function in mice. Molecules. 2010;15:3694-708. Switzerland

6. Zhao H-B, Lin S-Q, Liu J-H, Lin Z-B. Polysaccharide extract isolated from ganoderma lucidum protects rat cerebral cortical neurons from hypoxia/ reoxygenation injury. J Pharmacol Sci. 2004;95:294-8. Japan.

7. Cheung WM, Hui WS, Chu PW, Chiu SW, Ip NY. Ganoderma extract activates MAP kinases and induces the neuronal differentiation of rat pheochromocytoma PC12 cells. FEBS Lett. 2000;486:291-6. Netherlands.

8. Zhang J, Tang Q, Zhou C, Jia W, Da Silva L, Nguyen LD, et al. GLIS, a bioactive proteoglycan fraction from Ganoderma lucidum, displays antitumour activity by increasing both humoral and cellular immune response. Life Sci. 2010;87:628-37. Netherlands.

9. Lai CS-W, Yu M-S, Yuen W-H, So K-F, Zee S-Y, Chang RC-C. Antagonizing beta-amyloid peptide neurotoxicity of the anti-aging fungus Ganoderma lucidum. Brain Res. 2008;1190:215-24. Netherlands.

10. Zhou Y, Qu Z, Zeng Y, Lin Y, Li Y, Chung P, et al. Neuroprotective effect of preadministration with Ganoderma lucidum spore on rat hippocampus. Exp Toxicol Pathol. 2012;64:673-80. Germany.

11. Selkoe DJ. Alzheimer's disease: genotypes, phenotypes, and treatments. Science. 1997;275:630-1. United States.

12. Heneka MT, O'Banion MK. Inflammatory processes in Alzheimer's disease. J Neuroimmunol. 2007;184:69-91. Netherlands.

13. Perry VH, Nicoll JAR, Holmes C. Microglia in neurodegenerative disease. Nat Rev Neurol. 2010;6:193-201. England.

14. Brown GC, Neher JJ. Microglial phagocytosis of live neurons. Nat Rev Neurosci. 2014;15:209-16. England. 
15. Fu R, Shen Q, Xu P, Luo JJ, Tang Y. Phagocytosis of microglia in the central nervous system diseases. Mol Neurobiol. 2014;49:1422-34. United States.

16. Gerard C, Rollins BJ. Chemokines and disease. Nat Immunol. 2001;2:108-15. United States.

17. Gao L, Tang H, Nie K, Wang L, Zhao J, Gan R, et al. MCP-1 and CCR2 gene polymorphisms in Parkinson's disease in a Han Chinese cohort. Neurol Sci. 2015;36:571-6. Italy.

18. Nagata T, Nagano I, Shiote M, Narai H, Murakami T, Hayashi T, et al. Elevation of MCP-1 and MCP-1NEGF ratio in cerebrospinal fluid of amyotrophic lateral sclerosis patients. Neurol Res. 2007;29:772-6. England.

19. El Khoury JB, Moore KJ, Means TK, Leung J, Terada K, Toft M, et al. CD36 mediates the innate host response to beta-amyloid. J Exp Med. 2003;197: 1657-66. United States.

20. Hickman SE, El Khoury J. Mechanisms of mononuclear phagocyte recruitment in Alzheimer's disease. CNS Neurol Disord Drug Targets. 2010;9: 168-73. United Arab Emirates.

21. Selenica M-LB, Alvarez JA, Nash KR, Lee DC, Cao C, Lin X, et al. Diverse activation of microglia by chemokine ( $C-C$ motif) ligand 2 overexpression in brain. J Neuroinflammation. 2013;10:86. England.

22. Ishizuka K, Kimura T, Igata-yi R, Katsuragi S, Takamatsu J, Miyakawa T. Identification of monocyte chemoattractant protein-1 in senile plaques and reactive microglia of Alzheimer's disease. Psychiatry Clin Neurosci. 1997;51:135-8. Australia.

23. Wang P, Liao W, Fang J, Liu Q, Yao J, Hu M, et al. A glucan isolated from flowers of Lonicera japonica Thunb. inhibits aggregation and neurotoxicity of Abeta42. Carbohydr Polym. 2014;110:142-7. England.

24. Stine WB, Jungbauer $L, Y u C$, LaDu MJ. Preparing synthetic Abeta in different aggregation states. Methods Mol Biol. 2011;670:13-32. United States.

25. Hou Y, Wang Y, Zhao J, Li X, Cui J, Ding J, et al. Smart Soup, a traditional Chinese medicine formula, ameliorates amyloid pathology and related cognitive deficits. PLoS One. 2014;9:e111215. United States.

26. Lucin KM, O'Brien CE, Bieri G, Czirr E, Mosher Kl, Abbey RJ, et al. Microglial beclin 1 regulates retromer trafficking and phagocytosis and is impaired in Alzheimer's disease. Neuron. 2013;79:873-86. United States.

27. Kimmel CB, Ballard WW, Kimmel SR, Ullmann B, Schilling TF. Stages of embryonic development of the zebrafish. Dev Dyn. 1995;203:253-310. UNITED STATES.

28. Li Y, Du X, Pei G, Du J, Zhao J. beta-Arrestin1 regulates the morphology and dynamics of microglia in zebrafish in vivo. Eur J Neurosci. 2016;43:131-8. France.

29. Li Y, Du X-F, Liu C-S, Wen Z-L, Du J-L. Reciprocal regulation between resting microglial dynamics and neuronal activity in vivo. Dev Cell. 2012;23:1189202. United States.

30. Zhang R, Xu S, Cai Y, Zhou M, Zuo X, Chan P. Ganoderma lucidum protects dopaminergic neuron degeneration through inhibition of microglial activation. Evid Based Complement Alternat Med. 2011;2011:156810. United States

31. Hong S, Beja-Glasser VF, Nfonoyim BM, Frouin A, Li S, Ramakrishnan S, et al. Complement and microglia mediate early synapse loss in Alzheimer mouse models. Science. 2016;352:712-6. United States.

32. Macauley MS, Crocker PR, Paulson JC. Siglec-mediated regulation of immune cell function in disease. Nat Rev Immunol. 2014;14:653-66. Nature Publishing Group, a division of Macmillan Publishers Limited. All Rights Reserved. Available from: http://dx.doi.org/10.1038/nri3737.

33. Claude J, Linnartz-Gerlach B, Kudin AP, Kunz WS, Neumann H. Microglial CD33-related siglec-E inhibits neurotoxicity by preventing the phagocytosisassociated oxidative burst. J Neurosci. 2013;33:18270. LP - 18276. Available from: http://www.jneurosci.org/content/33/46/18270.abstract.

34. Kopatz J, Beutner C, Welle K, Bodea LG, Reinhardt J, Claude J, et al. Siglec-h on activated microglia for recognition and engulfment of glioma cells. Glia. 2013;61:1122-33. United States.

35. Neumann J, Sauerzweig S, Rönicke R, Gunzer F, Dinkel K, Ullrich O, et al. Microglia cells protect neurons by direct engulfment of invading neutrophil granulocytes: a new mechanism of CNS immune privilege. J Neurosci. 2008; 28:5965. LP - 5975. Available from: http://www.jneurosci.org/content/28/23/ 5965.abstract.

36. Nimmerjahn A, Kirchhoff F, Helmchen F. Resting microglial cells are highly dynamic surveillants of brain parenchyma in vivo. Science. 2005;308:1314-8. United States.

37. Kettenmann H, Hanisch U-K, Noda M, Verkhratsky A. Physiology of microglia. Physiol Rev. 2011;91:461-553. United States.
38. Rothwell N, Allan S, Toulmond S. The role of interleukin 1 in acute neurodegeneration and stroke: pathophysiological and therapeutic implications. J Clin Invest. 1997;100:2648-52.

39. Saha RN, Pahan K. Regulation of inducible nitric oxide synthase gene in glia cells. Antioxid Redox Signal. 2006;8:929-47. Available from: http://www.ncbi. nlm.nih.gov/pmc/articles/PMC1963415/.

40. Su F, Bai F, Zhang Z. Inflammatory cytokines and Alzheimer's disease: a review from the perspective of genetic polymorphisms. Neurosci Bull. 2016;32:469-80. China.

41. Swardfager W, Lanctot K, Rothenburg L, Wong A, Cappell J, Herrmann N. A meta-analysis of cytokines in Alzheimer's disease. Biol Psychiatry. 2010;68: 930-41. United States.

42. Zhou X, Spittau B, Krieglstein K. TGF $\beta$ signalling plays an important role in IL4-induced alternative activation of microglia. J Neuroinflammation. 2012:9:210. Available from: http://dx.doi.org/10.1186/1742-2094-9-210.

43. Wyss-Coray T, Lin C, Yan F, Yu GQ, Rohde M, McConlogue L, et al. TGFbeta1 promotes microglial amyloid-beta clearance and reduces plaque burden in transgenic mice. Nat Med. 2001;7:612-8. United States.

44. Huang S, Mao J, Ding K, Zhou Y, Zeng X, Yang W, et al. Polysaccharides from Ganoderma lucidum promote cognitive function and neural progenitor proliferation in mouse model of Alzheimer's disease. Stem Cell Rep. 2017:8:84-94. United States.

45. Kurpius D, Nolley EP, Dailey ME. Purines induce directed migration and rapid homing of microglia to injured pyramidal neurons in developing hippocampus. Glia. 2007;55:873-84. United States.

46. Tremblay M-Ė, Lowery RL, Majewska AK. Microglial interactions with synapses are modulated by visual experience. PLoS Biol. 2010;8. http://www. ncbi.nlm.nih.gov/pmc/articles/PMC2970556/.

47. Fontainhas AM, Wang M, Liang KJ, Chen S, Mettu P, Damani M, et al. Microglial morphology and dynamic behavior is regulated by ionotropic glutamatergic and GABAergic neurotransmission. Block M, editor. PLoS One. 2011;6:e15973. Available from: http://www.ncbi.nlm.nih.gov/pmc/articles/ PMC3026789/.

48. Morrison HW, Filosa JA. A quantitative spatiotemporal analysis of microglia morphology during ischemic stroke and reperfusion. J Neuroinflammation. 2013;10:4. England.

49. Cizkova D, Devaux S, Le Marrec-Croq F, Franck J, Slovinska L, Blasko J, et al. Modulation properties of factors released by bone marrow stromal cells on activated microglia: an in vitro study. Sci Rep. 2014;4:7514. England.

50. Peri F, Nüsslein-Volhard C. Live imaging of neuronal degradation by microglia reveals a role for v0-ATPase a1 in phagosomal fusion in vivo. Cell. 2008;133:916-27. Available from: http://www.sciencedirect.com/science/ article/pii/S0092867408006119.

51. Park H-C, Kim C-H, Bae Y-K, Yeo S-Y, Kim S-H, Hong S-K, et al. Analysis of upstream elements in the HuC promoter leads to the establishment of transgenic zebrafish with fluorescent neurons. Dev Biol. 2000;227:279-93. Available from: http://www.sciencedirect.com/science/article/pii/ S0012160600998981

52. Herbomel $P$, Thisse $B$, Thisse $C$. Zebrafish early macrophages colonize cephalic mesenchyme and developing brain, retina, and epidermis through a M-CSF receptor-dependent invasive process. Dev Biol. 2001;238:274-88. United States.

53. Herbomel $P$, Thisse B, Thisse C. Ontogeny and behaviour of early macrophages in the zebrafish embryo. Development. 1999;126:3735-45. England.

54. Harris JA, Devidze N, Halabisky B, Lo I, Thwin MT, Yu G-Q, et al. Many neuronal and behavioral impairments in transgenic mouse models of Alzheimer's disease are independent of caspase cleavage of the amyloid precursor protein. J Neurosci. 2010;30:372-81. United States.

55. Stevens B, Allen NJ, Vazquez LE, Howell GR, Christopherson KS, Nouri N, et al. The classical complement cascade mediates CNS synapse elimination. Cell. 2007;131:1164-78. United States.

56. Schafer DP, Lehrman EK, Kautzman AG, Koyama R, Mardinly AR, Yamasaki R, et al. Microglia sculpt postnatal neural circuits in an activity and complementdependent manner. Neuron. 2012;74:691-705. United States.

57. Stephan AH, Barres BA, Stevens B. The complement system: an unexpected role in synaptic pruning during development and disease. Annu Rev Neurosci. 2012;35:369-89. United States.

58. Neher JJ, Emmrich JV, Fricker M, Mander PK, Thery C, Brown GC. Phagocytosis executes delayed neuronal death after focal brain ischemia. Proc Natl Acad Sci U S A. 2013;110:E4098-107. United States. 
59. Fricker M, Oliva-Martin MJ, Brown GC. Primary phagocytosis of viable neurons by microglia activated with LPS or Abeta is dependent on calreticulin/LRP phagocytic signalling. J Neuroinflammation. 2012;9:196. England.

60. Neniskyte U, Neher JJ, Brown GC. Neuronal death induced by nanomolar amyloid beta is mediated by primary phagocytosis of neurons by microglia. J Biol Chem. 2011;286:39904-13. United States.

61. Kao AW, Eisenhut RJ, Martens LH, Nakamura A, Huang A, Bagley JA, et al. A neurodegenerative disease mutation that accelerates the clearance of apoptotic cells. Proc Natl Acad Sci U S A. 2011;108:4441-6. United States.

62. Marker DF, Puccini JM, Mockus TE, Barbieri J, Lu S-M, Gelbard HA. LRRK2 kinase inhibition prevents pathological microglial phagocytosis in response to HIV-1 Tat protein. J Neuroinflammation. 2012;9:261. England.

63. Guerreiro R, Wojtas A, Bras J, Carrasquillo M, Rogaeva E, Majounie E, et al. TREM2 variants in Alzheimer's disease. N Engl J Med. 2013;368:117-27. United States.

64. Naj AC, Jun G, Beecham GW, Wang L-S, Vardarajan BN, Buros J, et al. Common variants at MS4A4/MS4A6E, CD2AP, CD33 and EPHA1 are associated with late-onset Alzheimer's disease. Nat Genet. 2011;43:436-41. United States.

\section{Submit your next manuscript to BioMed Central} and we will help you at every step:

- We accept pre-submission inquiries

- Our selector tool helps you to find the most relevant journal

- We provide round the clock customer support

- Convenient online submission

- Thorough peer review

- Inclusion in PubMed and all major indexing services

- Maximum visibility for your research

Submit your manuscript at www.biomedcentral.com/submit 